PROFESSOR CORA BEATRIZ CYMERYNG (Orcid ID : 0000-0001-9586-3797)

Article type : Original Article

\title{
MELATONIN PREVENTS EARLY PITUITARY DYSFUNCTION INDUCED BY SUCROSE RICH DIETS
}

María Elisa Mercau ${ }^{1,4^{*}}$, Juan Salvador Calanni ${ }^{1}$, Marcos Luis Aranda ${ }^{1}$, Lilian Julia Caldareri ${ }^{1}$,

Ruth Estela Rosenstein $^{1,2}$, Esteban Martin Repetto ${ }^{1,3}$, Cora Beatriz Cymeryng ${ }^{1,2}$

*MEM and JSC equally contributed to this study.

1. Universidad de Buenos Aires. Consejo Nacional de Investigaciones Científicas y Técnicas (CONICET). Centro de Estudios Farmacológicos y Botánicos (CEFYBO). Facultad de Medicina. Buenos Aires, Argentina.

2. Universidad de Buenos Aires. Facultad de Medicina. Departamento de Bioquímica Humana. Buenos Aires, Argentina.

3. Universidad de Buenos Aires. Facultad de Farmacia y Bioquímica. Departamento de Bioquímica Clínica. Cátedra Bioquímica Clínica I. Buenos Aires, Argentina.

4. Current address: Department of Immunobiology, Yale University, New Haven, USA.

Running title: Melatonin blocks diet-induced ACTH secretion

This article has been accepted for publication and undergone full peer review but has not been through the copyediting, typesetting, pagination and proofreading process, which may lead to differences between this version and the Version of Record. Please cite this article as doi: $10.1111 /$ jpi. 12545

This article is protected by copyright. All rights reserved. 
Corresponding author: Cora B. Cymeryng. Departamento de Bioquímica Humana. Facultad de Medicina. Universidad de Buenos Aires. Paraguay $21555^{\circ}$ CABA ABG1121, Argentina. Email: cymeryng@fmed.uba or coracymeryng@gmail.com, TE: 54-11-52853249, FAX: 54$11-45083672(31)$.

Keywords: Pituitary; proopiomelanocortin, ACTH; glucocorticoids; melatonin; inflammation; oxidative stress; sucrose rich diet

\begin{abstract}
While physiological levels of glucocorticoids are required to ensure proper functions of the body, consistently high levels may engender several deleterious consequences. We have previously shown an increase in the activity of the hypothalamic-pituitary-adrenal (HPA) axis in rats fed sucrose rich diets (SRD). The main goal of this study was to analyze the processes involved in the modulation of the pituitary production of ACTH by SRD, and to test melatonin as a possible therapeutic agent for the prevention of the HPA axis dysfunction. Male Wistar rats were fed standard chow and either SRD (30\% sucrose in the drinking water) or plain water for three weeks. Melatonin was administered as subcutaneous pellets. Results showed that SRD treatment induced an increase in systemic ACTH and corticosterone levels and a decrease in melatonin levels. In the pituitary gland, we also detected an increase in the expression levels of proopiomelanocortin (POMC) that was accompanied by increased levels of: lipoperoxides, nitro-tyrosine modified proteins, catalase, heme oxygenase-1, interleukin$1 \beta$ mRNA, and by an increase in the tissue number of inflammatory cells (F4/80 and Iba-1 positive cells). Melatonin treatment prevented all these systemic and pituitary changes as well as the increase in POMC expression induced by incubation of AtT-20 corticotrophs with
\end{abstract}


conditioned media obtained from stimulated macrophages. In conclusion, stimulation of POMC/ACTH production in rats fed a SRD could involve the generation of oxidative stress and inflammation in the pituitary gland. Melatonin treatment prevented these effects and normalized the activity of the HPA axis.

\section{INTRODUCTION}

Glucocorticoids (GCs) exert essential roles on several aspects of normal cellular and physiological processes. In addition to their effects on glucose metabolism, GCs affect cell survival, proliferation, reproduction, growth, cognition, and behavior, also exerting regulatory effects on the cardiovascular, the immune, and the central nervous systems ${ }^{1,2}$. GCs, final effectors in the stress response, are synthesized and released by the adrenal cortex after binding of pituitary ACTH to specific melanocortin-2 receptors and activation of a downstream signaling pathway. ACTH is, in turn, a proteolytic processing product of the prohormone proopiomelanocortin (POMC), whose synthesis is induced by the hypothalamic peptides corticotropin-releasing hormone $(\mathrm{CRH})$ and arginine-vasopressin, upon activation of upper levels of the central nervous system.

Sustained excessive GC levels, as those present in patients with Cushing's syndrome, are associated with an increase in morbidity and mortality due to cardiovascular, thrombotic, metabolic, infectious and musculoskeletal complications ${ }^{3-5}$. Hypercortisolism has been ascribed in many of these patients to increased ACTH production by pituitary ACTHsecreting tumors ${ }^{6,7}$. Patients with hypercortisolism present with many of the characteristics of the metabolic syndrome, among them, visceral fat deposition, hyperglycemia, higher levels of plasma non-esterified free fatty acids, obesity and insulin resistance (IR) ${ }^{8-11}$. In fact, a role for GCs in the development and maintenance of obesity and IR syndrome has been 
suggested $^{12,13}$. Recently, we have demonstrated that the administration of a sucrose rich diet to Wistar rats (30\% sucrose in the drinking water, SRD) stimulates the activity of the hypothalamic-pituitary-adrenal (HPA) axis and induces insulin resistance (IR) after 7 weeks of treatment ${ }^{14}$.

Processing a high metabolic load, as in rats fed SRD, involves the generation of oxidative stress and inflammation as reported in adipose tissue and liver ${ }^{15,16}$. Moreover, the activity of the HPA axis has been shown to be modulated by reactive oxygen species (ROS) and cytokines $^{17-23}$. In particular, increased ACTH production by pituitary corticotroph cells incubated with cytokines ${ }^{24}$ or supraphysiological glucose concentrations through a ROSdependent mechanism has been demonstrated ${ }^{25}$.

Melatonin (5 methoxy- $N$-acetyltryptamine), the hormone mainly produced by the pineal gland is a multitasking molecule involved in multiple aspects of the physiological regulation of body functions such as circadian rhythms, immune responsiveness and reproductive activity in seasonally reproductive animals ${ }^{26-29}$. A large body of evidence indicates that melatonin is also a major scavenger of oxygen- and nitrogen-based reactive molecules at both physiologic and pharmacologic concentration ${ }^{30,31}$. Moreover, several intracellular enzymatic antioxidant enzymes, including superoxide dismutase, and glutathione peroxidase, among others, are stimulated by melatonin ${ }^{32-34}$. In addition to these many antioxidant properties, different lines of evidence demonstrate melatonin anti-inflammatory properties, such as a decrease in cytokine production and nitric oxide synthase- 2 inhibition ${ }^{35,36}$. In the present study, we analyzed the effect of SRD on the HPA axis activity at early stages of treatment (i.e., before the occurrence of IR). Moreover, since oxidant and inflammatory mechanisms 
could be involved in the effects of SRD on the synthesis and release of ACTH at pituitary level, we analyzed whether melatonin is able to abate HPA axis alterations.

\section{Materials and Methods}

\subsection{Animals}

Adult male Wistar rats (200-250g) were housed in groups (3 animals / cage) and maintained under controlled conditions of humidity and temperature $\left(21 \pm 2^{\circ} \mathrm{C}\right)$ under a $12 \mathrm{~h}$ light-dark cycle. Rats were fed a standard chow diet ad libitum and either tap water (Control group) or $30 \%$ sucrose in tap water $(30 \% \mathrm{w} / \mathrm{v}, \mathrm{SRD}$ groups). All protocols were approved by the Animal Care and Use Committee (CICUAL) from Facultad de Medicina, Universidad de Buenos Aires and followed the "Principles of laboratory animal care" (NIH publication no. 85-23, revised 1985).

\subsection{Melatonin treatment}

At the beginning of the experimental period indicated groups were implanted with a subcutaneous pellet of melatonin (20 mg with $3 \% \mathrm{w} / \mathrm{v}$ vegetable oil, compressed in a cylinder of $2.5 \mathrm{~mm}$ diameter and $1 \mathrm{~mm}$ length), while other groups were sham-operated without pellet implantation. The pellet of melatonin was implanted subcutaneously under the skin of the neck, and was replaced at mid-treatment ${ }^{37}$. Melatonin was obtained from Sigma Chemical Co. (St Louis, MO, USA).

\subsection{Tissue and serum samples}

Animals were sacrificed by decapitation, between 9 a.m. and 10 a.m., in order to minimize circadian variation among groups and trunk blood was collected. Anterior pituitary glands were dissected on ice and tissues were homogenized in $50 \mathrm{mmol} / \mathrm{L} \mathrm{Na}_{2} \mathrm{HPO}_{4} \mathrm{pH} 7.4,0.2$ 
mmol/L EDTA, 100 mmol/L KCl, 1X protease inhibitor cocktail (Sigma Aldrich, Argentina), or in TRI® reagent (Genbiotech, Argentina) for total RNA isolation.

\subsection{Biochemical and hormonal measurements}

Corticosterone levels were determined in serum samples by RIA after dichloromethane extraction, as described previously ${ }^{38}$. Plasma ACTH concentration was determined using Immulite $2000^{\circledR}$ (Siemens, Germany), and fasting serum glucose, triglyceride and NEFA levels were assessed by colorimetric commercial assays (Wiener Lab, Argentina and Randox, County Antrim, UK, respectively). Serum melatonin levels were analyzed via a competitive ELISA (IBL International Inc., Germany) according to the manufacturer's instructions. Blood samples for this assay were collected from the tail vein at zeitgeber time 18 (ZT18, $2 \mathrm{am})$.

\subsection{Oxidative stress parameters and antioxidant enzymes}

Pituitary tissues obtained from each animal were homogenized in $400 \mu \mathrm{l} 15 \mathrm{mM}$ $\mathrm{KH}_{2} \mathrm{PO}_{4} / \mathrm{K}_{2} \mathrm{PO}_{4}, 60 \mathrm{mM} \mathrm{KCl} \mathrm{pH} 7.4$ added with $1 \mathrm{X}$ protease inhibitors. Homogenates were centrifuged for $10 \mathrm{~min}$ at $1000 \mathrm{xg}$ at $4^{\circ} \mathrm{C}$ and supernatants were used. Lipid peroxide levels were determined as thiobarbituric acid reactive species (TBARS) as previously described ${ }^{39}$.

Catalase activity was determined according to published procedures ${ }^{40}$ with minor modifications. Briefly, pituitary homogenates were diluted 1:10 in $50 \mathrm{mM}$ sodium phosphate buffer $\mathrm{pH} 7.4$ and $100 \mu \mathrm{l}$ of this dilution were placed in a spectrophotometric cuvette. Reactions were initiated by the addition of $60 \mu \mathrm{l}$ of $2.5 \mathrm{Vol} \mathrm{H}_{2} \mathrm{O}_{2}(223 \mathrm{mM})$ and the absorbance at $240 \mathrm{~nm}$ was monitored for 120 seconds. Activity, expressed as $\mu \mathrm{M}$ of $\mathrm{H}_{2} \mathrm{O}_{2}$ consumed per min per mg protein, was calculated from the slope of the corresponding curve, considering a molar absorptivity of $0.0394 \mathrm{mM}^{-1} \mathrm{~cm}^{-1}$ for $\mathrm{H}_{2} \mathrm{O}_{2}$. 


\subsection{Immunohistochemistry}

Animals were anesthetized with a ketamine and xylazine cocktail $(50 \mathrm{mg} / \mathrm{kg}$ and $2 \mathrm{mg} / \mathrm{kg}$ respectively) and intracardially perfused with $4 \%$ paraformaldehyde in $0.1 \mathrm{M}$ sodium phosphate buffer $\mathrm{pH}$ 7.4. Pituitary tissues were dissected, post-fixed in the same fixative for $12 \mathrm{~h}$ and dehydrated by incubating with solutions of increasing ethanol concentration $(70 \%$, $90 \%$ and $100 \% \mathrm{v} / \mathrm{v})$. Tissues were clarified with N-butyl acetate and embedded in paraffin (Biopack, Argentina). Pituitary glands were serially sliced in $4 \mu \mathrm{m}$ sections using a rotating microtome (RM2125 RTS, Leica, Germany) with every section collected on charged slides and then dehydrated by heat $\left(50^{\circ} \mathrm{C}\right.$ for $\left.10 \mathrm{~min}\right)$. After deparaffinization and rehydration, antigen retrieval was performed by incubating the sections in citrate buffer (10 mM sodium citrate, $0.05 \%$ Tween-20 $\mathrm{pH} 6.3$ ) for $30 \mathrm{~min}$ at $100^{\circ} \mathrm{C}$. Tissue permeabilization was induced by incubating the sections with $0.3 \%$ Triton $\mathrm{X}-100$ in $1 \mathrm{X}$ PBS. After three washes with $1 \mathrm{X}$ PBS sections were incubated for $1 \mathrm{~h}$ in a blocking solution (2\% normal horse serum). Immunodetection was performed with rabbit anti-ACTH (1:1000, Santa Cruz Biotechnology Cat\# sc-52980, RRID: AB_831670) or anti-Iba-1 (1:500, Abcam Cat\# ab5076, RRID: AB_2224402) in $1 \mathrm{X}$ PBS, overnight at $4^{\circ} \mathrm{C}$ in a humid chamber. For secondary detection, sections were incubated for $2 \mathrm{~h}$ at room temperature in a dark chamber with fluorescent-dye conjugated secondary antibodies (Abcam Cat\# ab150129, RRID: AB_2687506). Slides were mounted with fluorescence media with DAPI (Vectashield, Vector Laboratories, USA) and images were acquired in a fluorescence microscope (BX-50 Olympus, USA), through an incorporated digital camera (3CCD, Sony, USA) and processed with Image J software (NIH, Bethesda, MD, USA). The number of Iba-1 positive cells was counted in an area of $500 \times 500$ pixels (12 images per treatment).

This article is protected by copyright. All rights reserved. 
2.7 Reverse Transcription and quantitative real time polymerase chain reaction (RT-qPCR) assays

Reverse transcription was performed using MMLV reverse transcriptase (Life Technologies, Argentina) as previously described ${ }^{41}$. Amplifications by qPCR were carried out in a RotorGene 6000 Corbett Life Science Real Time Thermal Cycler (Corbett Research, Sidney, NSW, Australia) and quantified with the Rotor Gene 6000 Series Software (version 1.7 Build 40, Hilden, Germany). Primer oligonucleotide sequences used in this study are listed in Supplementary Table 1. Gene expression levels were normalized to Actb ( $\beta$-Actin) as an internal control, using the $\Delta \Delta \mathrm{Ct}$ relative quantification method ${ }^{42}$.

\subsection{Immunoblot analysis}

Pituitary homogenates were resolved by SDS-PAGE and transferred to polyvinylidinefluoride membranes in a Trans-Blot Semi-Dry system (Bio-Rad Laboratories Inc., USA). PVDF membranes were blocked in $20 \mathrm{mM}$ Tris- $\mathrm{HCl}(\mathrm{pH} 7.4), 137 \mathrm{mM} \mathrm{NaCl}, 0.1 \%$ Tween 20 , and $5 \%$ nonfat milk for $60 \mathrm{~min}$ at room temperature and then incubated overnight with the indicated dilution of the following antisera at $4^{\circ} \mathrm{C}$ : 1:2500 mouse ACTH mAb (Santa Cruz Biotechnology Cat\# sc-52980, RRID:AB_831670), 1:2000 rabbit Nitro-tyrosine pAb (SigmaAldrich Cat\# N0409, RRID:AB_260745), 1:1000 rabbit heme oxygenase-1 (HO-1) pAb (Enzo Life Sciences Cat\# ADI-SPA-896, RRID:AB_10614948), 1:1000 rabbit F4/80 pAb (Santa Cruz Biotechnology Cat\# sc-25830, RRID:AB_2246477) and 1:1000 mouse actin mAb (Santa Cruz Biotechnology Cat\# sc-47778 HRP, RRID:AB_2714189). Membranes were then incubated with a 1:20000 dilution of either Goat anti-Rabbit IgG (Bio-Rad / AbD Serotec $\mathrm{Cat}^{\#}$ 170-6515, RRID:AB_11125142) or Horse anti-Mouse IgG horseradish peroxidase conjugate (Cell Signaling Technology Cat\# 7076, RRID:AB_330924) as described elsewhere ${ }^{43}$. Chemiluminescence was detected with the Image Quant Imaging 
System (GE Healthcare, PA, USA) and quantification was performed using Image $\mathbf{J}$ software (NIH, Bethesda, MD, USA).

\subsection{Cell Lines and Culture Conditions}

The mouse ACTH-secreting pituitary adenoma cell line, AtT-20/D16v-F2 (named AtT-20 hereafter $)^{44}$ was obtained from the American Type Culture Collection (ATCC, Manassas, USA). AtT-20 cells were maintained in Dulbecco's Modified Eagle's Medium (DMEMInvitrogen, Argentina) supplemented with $10 \%$ heat-inactivated fetal bovine serum (FBS) and $100 \mathrm{U} / \mathrm{ml}$ penicillin, $100 \mu \mathrm{g} / \mathrm{ml}$ streptomycin at $37^{\circ} \mathrm{C}$ and $5 \% \mathrm{CO}_{2}$. All treatments were performed in serum-free DMEM.

Mouse macrophage-like cells, J774.1, were kindly provided by Dr. Alejandra Goldman (Universidad Nacional de San Martín, Argentina) and maintained in DMEM medium supplemented with $100 \mathrm{U} / \mathrm{mL}$ of penicillin, $100 \mu \mathrm{g} / \mathrm{mL}$ of streptomycin, $100 \mathrm{U} / \mathrm{ml}$ amphotericin $\mathrm{B}$ and $10 \% \mathrm{FBS}$ at $37{ }^{\circ} \mathrm{C}$ and $5 \% \mathrm{CO}_{2} . \mathrm{J} 774.1$ cells were incubated in the presence or absence of $100 \mathrm{ng} / \mathrm{ml}$ LPS (Escherichia coli endotoxin, serotype O111:B4) and $7.5 \mathrm{mM}$ D-glucose and $50 \mathrm{nM}$ melatonin. After $6 \mathrm{~h}$, the cells were washed three times with PBS, and the medium was replaced with complete culture medium. After culturing the cells for another $24 \mathrm{~h}$ the conditioned media were collected, centrifuged at $1950 \mathrm{~g}$ for $20 \mathrm{~min}$, and then filtered through 0.22- $\mu$ m-pore filters (Millipore, Billerica, MA, USA) to remove cells and debris.

Cell viability, assessed by the Trypan-blue exclusion method, was calculated as \% ratio of viable cells (unstained) to total cells. None of the treatments described in this study affected cell viability assessed by Trypan-blue exclusion method. 


\subsection{Transfections and reporter assays}

AtT-20 cells were seeded in 96-well plates $\left(10^{4}\right.$ cells per well) and transfected using Lipofectamine $2000^{\circledR}$ (Invitrogen Argentina, Argentina), pPOMC-pGL3 and pGL3-NFkB-

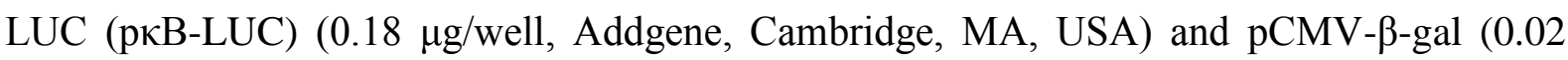
$\mu \mathrm{g} /$ well) following manufacturer's instructions. Luciferase activity was determined using the Steady-Glo Luciferase Assay System (Promega Corporation, Madison, WI, USA). Values were normalized to $\beta$-galactosidase activity. pPOMC-pGL3 was provided by Dr. Domenico

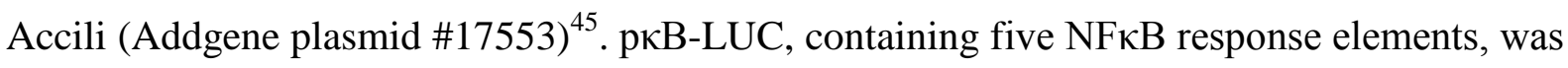
kindly provided by Dr. Omar Coso (FCEyN, UBA, Argentina) ${ }^{46}$.

\subsection{Statistical Analysis}

Data is presented as mean \pm standard error of the mean. Differences between groups were analyzed by two-tailed unpaired Student's $t$ test or by one-way ANOVA, as appropriate. When the ANOVA yielded significant differences $(\mathrm{p}<0.05)$, post hoc comparisons (Tukey's tests) were made to determine the statistical difference between groups. All calculations were performed using Prism 7 for Mac OSX Version 7.0a (GraphPad Software, CA, USA).

\section{Results}

\subsection{Early functional changes in pituitary glands from SRD-treated animals}

Figure 1 shows significantly higher systemic levels of ACTH and corticosterone after a short treatment with SRD (Figure 1A and 1B, respectively) compared to controls. Accordingly, increased levels of Pomc mRNA (Figure 1C) and ACTH protein (Figure 1D) were detected in pituitary tissues from SRD-treated rats. Interestingly, after three weeks of SRD a significant decrease in nocturnal serum melatonin levels was detected (Control: $160.7 \pm 18.2 \mathrm{pg} / \mathrm{ml} \mathrm{n}=4$,

SRD: $98.9 \pm 8.2 \mathrm{pg} / \mathrm{ml} \mathrm{n}=6 \mathrm{p}=0.0081)$.

This article is protected by copyright. All rights reserved. 
As shown in Figure 2, three weeks of treatment with SRD induced an increase in pituitary TBARS levels (Figure 2A), catalase activity (Figure 2B), hemoxygenase-1 (HO-1) expression levels (Figure 2C) and nitrotyrosine-modified protein immunoreactivity (data not shown). In addition, an immunohistochemical analysis indicated a significantly higher number of Iba-1 (+) cells in the pituitary glands obtained from SRD-treated rats (Figure 2D). An increase in the protein levels of F4/80, a macrophage marker (Figure 2E), in mRNA levels of $I l l b$ and the inflammasome components Asc and Nalp3 (Figure 2F) and in the mRNA levels of Tnfa (data not shown) were also observed in this group.

\subsection{Preventive effects of melatonin treatment on SRD-induced pituitary dysfunction}

Table 1 shows that rats fed a SRD for three weeks exhibited significantly higher fasting serum levels of glucose, non-esterified fatty acids (NEFA), and TAG, without significant differences in body weights compared to the corresponding controls. The administration of melatonin did not affect these parameters either in control or in SRD-treated rats.

Melatonin treatment prevented the SRD-dependent increase in pituitary lipid peroxides (Figure 2A), catalase activity (Figure 2B) and HO-1 (Figure 2C) protein levels. In addition, melatonin also blocked the increase in Iba-1-immunoreactivity (Figure 2D) and F4/80-protein levels (Figure 2E) in pituitary glands from SRD-treated rats. The SRD-dependent increase in the pituitary expression of $I l l b$ and the inflammasome components Asc, Nalp3, was also prevented by melatonin (Figure $2 \mathrm{~F}$ ). In addition, melatonin treatment suppressed the SRDinduced increase in ACTH protein levels (Figure 3A) as well as in systemic levels of ACTH (Figure 3B) and corticosterone (Figure 3C).

This article is protected by copyright. All rights reserved. 


\subsection{Effects of melatonin on the immune-endocrine interactions that lead to increased POMC/ACTH expression in AtT-20 cells.}

In order to test whether inflammatory mediators could contribute to the induction of Pomc, we treated corticotroph cells (AtT-20) with conditioned media (CM) obtained from mouse J774 macrophages stimulated with LPS (100 ng/ml) and/or moderately high glucose levels (D-Glu, $7.5 \mathrm{mM})$ in the presence or absence of melatonin $(50 \mathrm{nM})$ (Figure 4A). This treatment resulted in a seven-fold increase in $I l 1 b$ levels in J774 cells (data not shown). As indicated in Figure $4 \mathrm{~B}$ and C, when AtT-20 cells were incubated with CM obtained from macrophages stimulated with LPS+GLU, luciferase activity of the reporter plasmids pкB-Luc (Figure 4B) and POMC-pGL3 (Figure 4C) was significantly increased. Similar results were obtained by analyzing ACTH expression levels by immunoblot (Figure 4D). These effects were not observed when CM was obtained from macrophages stimulated with LPS+Glu in the presence of melatonin (Figures 4B-D).

\section{Discussion}

Our results indicate that a short-term SRD administration (three weeks) induced significant changes in the activity of the HPA axis including an increase in systemic ACTH and corticosterone concentrations that correlated with elevated levels of Pomc and ACTH at the pituitary level. In addition, the occurrence of oxidative stress and inflammation was detected in the adenohypophysis of these animals. Present results also indicate that a treatment with melatonin prevented the SRD-dependent induction of oxidative stress and inflammation in the adenohypophysis and normalized the activity of the HPA axis. Moreover, since SRD decreased serum melatonin levels, it is tempting to speculate that decreased endogenous melatonin levels could contribute to the pituitary dysfunction described herein. 
Previous studies support an important role of melatonin as a physiological regulator of the HPA axis in animals. In this line, early reports have shown an increase in corticosterone levels in young pinealectomized animals, that is lost in old rats ${ }^{47}$. The involvement of an agerelated decrease in melatonin production ${ }^{48}$ in the higher corticosterone levels in old rats was suggested. In agreement, studies by Konakchieva et al. $^{49,50}$ demonstrated that melatonin administration for 5 days significantly reduces corticosterone secretion, attenuates the adrenocortical response to stress and increases HPA axis sensitivity to glucocorticoid suppression. Melatonin treatment decreases corticosterone levels in a mice model of chronic mild stress ${ }^{51}$ and CRH, ACTH, corticosterone, and cytokine levels) in LPS-treated diabetic (STZ) rats ${ }^{52}$. More recently, Zhou et al. have shown that melatonin or MT1/MT2 agonists (piromelatin or Neu-P11) decrease urinary corticosterone levels in high-fat fed rats under chronic stress or in diabetic rats ${ }^{53,54}$.

Several reports have demonstrated that increased nutrient availability generates oxidative stress as a result of ROS/RNS production from mitochondria and other sources that surpasses the antioxidant capacity of the tissue ${ }^{55-57}$. Since SRD-treatment induced higher systemic levels of glucose, TAG and NEFA, it seems likely that an increased supply of nutrients could lead to the generation of oxidative stress, leading in turn to a pituitary dysfunction. In this regard, here we show an increase in lipid peroxidation along with the induction of catalase, and HO-1 in the pituitary gland from SRD-treated rats.

Oxidative stress has been associated with the generation of a low grade inflammatory state in the liver, the adipose tissue, and other tissues (for review see ${ }^{58,59}$ ). In particular, an increase in the number of adipose tissue macrophages has been linked to the expansion and inflammation of the adipose tissue, and to the occurrence of IR and type 2 diabetes (for review see ${ }^{60}$ ). 
Activation of tissue macrophages in IR animals is not restricted to adipose tissue, as it has been also demonstrated in liver, skeletal muscle, and pancreatic islets ${ }^{60}$. In agreement, our results showed that administration of a SRD for three weeks provoked an increase in the number of pituitary macrophages, the induction of inflammasome-associated proteins, and the expression levels of IL1- $\beta$ in the pituitary gland. Although both M1 and M2-like macrophages have been detected in the anterior pituitary gland from control rats ${ }^{61}$, the increase in $I l l b$ production in the adenohypophysis of SRD-treated rats suggests an imbalance in favor of pro-inflammatory macrophages.

Since both oxidative and inflammatory mechanisms could be involved in the development of the diet-induced pituitary dysfunction, we next wonder if a treatment with melatonin, a wellknown antioxidant and anti-inflammatory molecule, could prevent the early dysregulation of the HPA axis induced by the administration of $\mathrm{SRD}^{32,35}$. Several reports have indicated that melatonin administration could decrease glycemia, as well as serum cholesterol and TAG levels ${ }^{62-64}$. In our study, melatonin administered as a subcutaneous pellet throughout the duration of the experimental period, following a protocol previously validated ${ }^{37,65,66}$, did not affect these biochemical parameters. This discrepancy could be due to differences in administration routes, dosages and treatment duration. Nevertheless, melatonin treatment was effective in preventing the generation of oxidative stress in the adenohypophysis of SRDtreated rats (as shown by a decrease in lipoperoxide levels). As the induction of the antioxidant defense system could be triggered by ROS, this effect of melatonin could also account for the significant decrease in the levels of antioxidant enzymes.

This article is protected by copyright. All rights reserved. 
Macrophages can induce non-infectious inflammatory reactions through the recognition of danger-associated molecular patterns (DAMPs) released upon cellular injury. Binding of DAMPs to pattern-recognition receptors activates different intracellular pathways. Among them, activation of the NLP3-inflammasome pathway leads to the production of IL-1 $\beta$ and IL-18 ${ }^{67-69}$. Several studies have demonstrated the association between inflammasome activation and obesity-induced inflammation, insulin resistance, type 2 diabetes ${ }^{70-72}$, acute and chronic liver diseases ${ }^{73,74}$, and diabetic nephropathies ${ }^{75}$. Our results on the activation of the NLP3-inflammasome are, to our knowledge, the first report on the activation of this pathway in the pituitary gland of rats fed a SRD. Melatonin treatment not only prevented the increase in the number of macrophages but also blocked the induction of IL-1 $\beta$ and components of the NLP3-inflammasome in the adenohypophysis. In agreement with our results, prevention of NLP3-inflammasome activation by melatonin has been demonstrated in inflammatory diseases and sepsis ${ }^{35,76,77}$. In harmony with these results, melatonin has been shown to favor the anti-inflammatory M2 phenotype over M1 in liver Kupffer cells, peritoneal macrophages, and splenocytes from stressed mice ${ }^{78}$.

Our hypothesis on the involvement of oxidative/inflammatory effects in the pituitary dysfunction seems to be consistent with the melatonin-induced prevention of the increase in pituitary and systemic levels of ACTH and corticosterone in SRD-treated rats.

DAMPs generated within the pituitary gland as a consequence of the deleterious effects of ROS/RNS on cellular components, could attract and stimulate macrophages to produce cytokines that in turn impact on POMC production by corticotrophs. We thus speculate that a cross-talk could be established within the pituitary gland between activated tissue macrophages and corticotrophs. This hypothesis was supported by the results of experiments 
in which AtT-20 cells were incubated with conditioned media obtained from macrophages activated with LPS and mild supraphysiological glucose concentrations. In these experimental setting we observed the stimulation of the NFKB pathway and the induction of POMC expression in AtT-20 cells. Similar results were obtained when these cells were incubated in the presence of IL-1 $\beta$ and other cytokines ${ }^{20,24}$. Since melatonin treatment of macrophages prevented the stimulatory effect of conditioned media on POMC expression in AtT-20 corticotrophs, we suggest that by inhibiting the production of IL-1 $\beta$ (by blocking inflammasome activation $)^{79,80}$ or other cytokines by local macrophages, as previously demonstrated in RAW264.7 cells ${ }^{81}$, melatonin could prevent the simulation of POMC/ACTH by pituitary corticotrophs in SRD-treated rats. An additional effect of melatonin in preventing ROS-dependent negative feed-back regulation of glucocorticoids on corticotroph POMC production as described by Asaba et al. ${ }^{82}$ could not be discarded.

As previously indicated, melatonin effects on cellular physiology involves a variety of mechanisms. Some of them implicate its binding to specific receptors followed by activation of signal transduction pathways. However, melatonin exerts many of its antioxidant and antiinflammatory effects by receptor-independent effects ${ }^{83,84}$. In favor of this mechanism, Johnston et al. $^{85}$ demonstrated the expression of melatonin type 1 receptors (MT1) receptors in the rat fetal pituitary pars distalis which declines after birth, while other studies demonstrated a weak staining of MT1 receptors in this area (but a strong one in pars tuberalis $)^{86}$, while the presence of melatonin receptors has been demonstrated in brain areas that could modulate the activity of the HPA axis ${ }^{86,87}$. Nonetheless, Jusczak et al. ${ }^{88}$ showed that intracerebroventricular infusion of melatonin resulted in a significant decrease in rat plasma ACTH levels that could not be blocked by receptor antagonists (luzindole or 4phenyl-2-propionamidotetralin). Notwithstanding, Fischer et al. demonstrated that an acute 
treatment with melatonin $(2.5 \mathrm{~h})$ in mice stimulated POMC expression in the pituitary pars distalis, an effect that was not observed in $\mathrm{MT}^{-/-}$mice ${ }^{89}$. Altogether, melatonin could affect HPA axis activity by exerting direct effects on pituitary pars distalis (receptor-independent) by interacting with MT1/MT2 receptors, by other mechanisms (e.g., free radical scavenger, interaction with orphan nuclear receptors and molecules, as calmodulin) or by a combination of some or all the above. The complexity of the processes involved makes it difficult to determine the precise contribution of each mechanism to the effect of melatonin on the HPA axis activity. This issue will be explored in future studies.

In summary, present results suggest that the diet-induced metabolic burden imposed on the anterior pituitary gland generates oxidative stress and inflammation. As a result of the deleterious effects associated with the production of ROS/RNS, metabolites or damaged cellular components released to the extracellular medium signal the recruitment of circulating monocytes and activate tissue macrophages to produce cytokines. These effectors, in turn, stimulate the synthesis of POMC and ACTH by pituitary corticotrophs. By preventing the diet-induced HPA axis dysfunction, melatonin appears to be a suitable therapeutic option to attenuate the metabolic effects of glucocorticoid overproduction.

\section{Acknowledgments}

This study was supported by grants from CONICET (PIP0257CO), Sociedad Argentina de Diabetes, ANPCyT (PICT $2015 \mathrm{~N}^{\circ}$ 1008) and Universidad de Buenos Aires (UBACyT20020130100115BA). The authors would like to thank Dr. Carla Rothlin and Dr. Sourav Ghosh from Yale University for their generous contribution to this study. 
Author contributions

MEM and JSC: acquisition of data, data analysis/interpretation and preparation of figures and tables. MLA and LC: animal experiments with melatonin and immunohistochemical analysis. MEM and EMR: experimental design and supervision of data analysis. RER: discussion of results and preparation of the manuscript. $\mathrm{CBC}$ : experimental design, supervision of data analysis, discussion of results and preparation of the manuscript.

\section{References}

1. Munck A, Guyre PM. Glucocorticoid physiology, pharmacology and stress. Adv Exp Med Biol. 1986;196:81-96.

2. Wilckens T. Glucocorticoids and immune function: physiological relevance and pathogenic potential of hormonal dysfunction. Trends Pharmacol Sci. 1995;16(6):193197.

3. Etxabe J, Vazquez JA. Morbidity and mortality in Cushing's disease: an epidemiological approach. Clin Endocrinol (Oxf). 1994;40(4):479-484.

4. Colao A, Pivonello R, Spiezia S, et al. Persistence of increased cardiovascular risk in patients with Cushing's disease after five years of successful cure. J Clin Endocrinol Metab. 1999;84(8):2664-2672.

5. Neary NM, Booker OJ, Abel BS, et al. Hypercortisolism is associated with increased coronary arterial atherosclerosis: analysis of noninvasive coronary angiography using multidetector computerized tomography. J Clin Endocrinol Metab. 2013;98(5):20452052.

6. Miyachi Y. Pathophysiology and diagnosis of Cushing's syndrome. Biomed Pharmacother. 2000;54 Suppl 1:113s-117s.

7. Shomali ME, Hussain MA. Cushing's syndrome: from patients to proteins. Eur $J$ Endocrinol. 2000;143(3):313-315.

8. Pivonello R, Isidori AM, De Martino MC, Newell-Price J, Biller BM, Colao A. Complications of Cushing's syndrome: state of the art. Lancet Diabetes Endocrinol. 2016;4(7):611-629.

9. Lee MJ, Pramyothin P, Karastergiou K, Fried SK. Deconstructing the roles of glucocorticoids in adipose tissue biology and the development of central obesity. Biochim Biophys Acta. 2014;1842(3):473-481.

10. Krikorian A, Khan M. Is metabolic syndrome a mild form of Cushing's syndrome? Rev Endocr Metab Disord. 2010;11(2):141-145.

11. Chanson P, Salenave S. Metabolic syndrome in Cushing's syndrome. Neuroendocrinology. 2010;92 Suppl 1:96-101.

12. Arnaldi G, Scandali VM, Trementino L, Cardinaletti M, Appolloni G, Boscaro M. Pathophysiology of dyslipidemia in Cushing's syndrome. Neuroendocrinology. 2010;92 Suppl 1:86-90.

This article is protected by copyright. All rights reserved. 
13. Peeke PM, Chrousos GP. Hypercortisolism and obesity. Ann $N$ Y Acad Sci. 1995;771:665-676.

14. Martinez Calejman C, Di Gruccio JM, Mercau ME, et al. Insulin sensitization with a peroxisome proliferator-activated receptor gamma agonist prevents adrenocortical lipid infiltration and secretory changes induced by a high-sucrose diet. $J$ Endocrinol. 2012;214(3):267-276.

15. Tan BL, Norhaizan ME, Liew WP. Nutrients and Oxidative Stress: Friend or Foe? Oxid Med Cell Longev. 2018;2018:9719584.

16. Jegatheesan P, De Bandt JP. Fructose and NAFLD: The Multifaceted Aspects of Fructose Metabolism. Nutrients. 2017;9(3).

17. Path G, Scherbaum WA, Bornstein SR. The role of interleukin-6 in the human adrenal gland. Eur J Clin Invest. 2000;30 Suppl 3:91-95.

18. Boutzios G, Kaltsas G. Immune System Effects on the Endocrine System. 2000.

19. Villar SR, Ronco MT, Fernandez Bussy R, et al. Tumor necrosis factor-alpha regulates glucocorticoid synthesis in the adrenal glands of Trypanosoma cruzi acutely-infected mice. the role of TNF-R1. PLoS One. 2013;8(5):e63814.

20. Katahira M, Iwasaki Y, Aoki Y, Oiso Y, Saito H. Cytokine regulation of the rat proopiomelanocortin gene expression in AtT-20 cells. Endocrinology. 1998;139(5):24142422.

21. Kariagina A, Romanenko D, Ren SG, Chesnokova V. Hypothalamic-pituitary cytokine network. Endocrinology. 2004;145(1):104-112.

22. Chesnokova V, Melmed S. Minireview: Neuro-immuno-endocrine modulation of the hypothalamic-pituitary-adrenal (HPA) axis by gp130 signaling molecules. Endocrinology. 2002;143(5):1571-1574.

23. Tkachenko IV, Jaaskelainen T, Jaaskelainen J, Palvimo JJ, Voutilainen R. Interleukins 1alpha and 1beta as regulators of steroidogenesis in human NCI-H295R adrenocortical cells. Steroids. 2011;76(10-11):1103-1115.

24. Takayasu S, Iwasaki Y, Nigawara T, et al. Involvement of nuclear factor-kB and Nurr-1 in cytokine-induced transcription of proopiomelanocortin gene in AtT20 corticotroph cells. Neuroimmunomodulation. 2010;17(2):88-96.

25. Asaba K, Iwasaki Y, Asai M, et al. High glucose activates pituitary proopiomelanocortin gene expression: possible role of free radical-sensitive transcription factors. Diabetes Metab Res Rev. 2007;23(4):317-323.

26. Tordjman S, Chokron S, Delorme R, et al. Melatonin: Pharmacology, Functions and Therapeutic Benefits. Curr Neuropharmacol. 2017;15(3):434-443.

27. Reiter RJ, Tan DX, Manchester LC, Paredes SD, Mayo JC, Sainz RM. Melatonin and reproduction revisited. Biol Reprod. 2009;81(3):445-456.

28. Reiter RJ, Maestroni GJ. Melatonin in relation to the antioxidative defense and immune systems: possible implications for cell and organ transplantation. J Mol Med (Berl). 1999;77(1):36-39.

29. Erren TC, Reiter RJ, Piekarski C. Light, timing of biological rhythms, and chronodisruption in man. Naturwissenschaften. 2003;90(11):485-494.

30. Zhang HM, Zhang Y. Melatonin: a well-documented antioxidant with conditional prooxidant actions. J Pineal Res. 2014;57(2):131-146.

31. Reiter RJ, Tan DX, Galano A. Melatonin reduces lipid peroxidation and membrane viscosity. Front Physiol. 2014;5:377.

32. Reiter RJ, Mayo JC, Tan DX, Sainz RM, Alatorre-Jimenez M, Qin L. Melatonin as an antioxidant: under promises but over delivers. J Pineal Res. 2016;61(3):253-278.

33. Sharafati-Chaleshtori R, Shirzad H, Rafieian-Kopaei M, Soltani A. Melatonin and human mitochondrial diseases. J Res Med Sci. 2017;22:2.

This article is protected by copyright. All rights reserved. 
34. Vriend J, Reiter RJ. The Keap1-Nrf2-antioxidant response element pathway: a review of its regulation by melatonin and the proteasome. Mol Cell Endocrinol. 2015;401:213-220.

35. Favero G, Franceschetti L, Bonomini F, Rodella LF, Rezzani R. Melatonin as an AntiInflammatory Agent Modulating Inflammasome Activation. Int $J$ Endocrinol. 2017;2017:1835195.

36. Korkmaz A, Reiter RJ, Topal T, Manchester LC, Oter S, Tan DX. Melatonin: an established antioxidant worthy of use in clinical trials. Mol Med. 2009;15(1-2):43-50.

37. Salido EM, Bordone M, De Laurentiis A, et al. Therapeutic efficacy of melatonin in reducing retinal damage in an experimental model of early type 2 diabetes in rats. $J$ Pineal Res. 2013;54(2):179-189.

38. Cymeryng CB, Dada LA, Podesta EJ. Effect of nitric oxide on rat adrenal zona fasciculata steroidogenesis. The Journal of endocrinology. 1998;158(2):197-203.

39. Ohkawa H, Ohishi N, Yagi K. Assay for lipid peroxides in animal tissues by thiobarbituric acid reaction. Anal Biochem. 1979;95(2):351-358.

40. Aebi H. Catalase. Wenheim, Germany: Verlag Chemie; 1982.

41. Mercau ME, Astort F, Giordanino EF, et al. Involvement of PI3K/Akt and p38 MAPK in the induction of COX-2 expression by bacterial lipopolysaccharide in murine adrenocortical cells. Molecular and cellular endocrinology. 2014;384(1-2):43-51.

42. Livak KJ, Schmittgen TD. Analysis of relative gene expression data using real-time quantitative PCR and the 2(-Delta Delta C(T)) Method. Methods. 2001;25(4):402-408.

43. Mercau ME, Repetto EM, Perez MN, et al. Moderate Exercise Prevents Functional Remodeling of the Anterior Pituitary Gland in Diet-Induced Insulin Resistance in Rats: Role of Oxidative Stress and Autophagy. Endocrinology. 2016;157(3):1135-1145.

44. Gumbiner B, Kelly RB. Two distinct intracellular pathways transport secretory and membrane glycoproteins to the surface of pituitary tumor cells. Cell. 1982;28(1):51-59.

45. Kitamura T, Feng Y, Kitamura YI, et al. Forkhead protein FoxO1 mediates Agrpdependent effects of leptin on food intake. Nat Med. 2006;12(5):534-540.

46. Squarize CH, Castilho RM, Sriuranpong V, Pinto DS, Jr., Gutkind JS. Molecular crosstalk between the NFkappaB and STAT3 signaling pathways in head and neck squamous cell carcinoma. Neoplasia. 2006;8(9):733-746.

47. Oxenkrug GF, McIntyre IM, Gershon S. Effects of pinealectomy and aging on the serum corticosterone circadian rhythm in rats. J Pineal Res. 1984;1(2):181-185.

48. Reiter RJ, Craft CM, Johnson JE, Jr., et al. Age-associated reduction in nocturnal pineal melatonin levels in female rats. Endocrinology. 1981;109(4):1295-1297.

49. Konakchieva R, Mitev Y, Almeida OF, Patchev VK. Chronic melatonin treatment and the hypothalamo-pituitary-adrenal axis in the rat: attenuation of the secretory response to stress and effects on hypothalamic neuropeptide content and release. Biol Cell. 1997;89(9):587-596.

50. Konakchieva R, Mitev Y, Almeida OF, Patchev VK. Chronic melatonin treatment counteracts glucocorticoid-induced dysregulation of the hypothalamic-pituitary-adrenal axis in the rat. Neuroendocrinology. 1998;67(3):171-180.

51. Detanico BC, Piato AL, Freitas JJ, et al. Antidepressant-like effects of melatonin in the mouse chronic mild stress model. Eur J Pharmacol. 2009;607(1-3):121-125.

52. Zhong LY, Yang ZH, Li XR, Wang H, Li L. Protective effects of melatonin against the damages of neuroendocrine-immune induced by lipopolysaccharide in diabetic rats. Exp Clin Endocrinol Diabetes. 2009;117(9):463-469.

53. Zhou J, Wang D, Luo X, et al. Melatonin Receptor Agonist Piromelatine Ameliorates Impaired Glucose Metabolism in Chronically Stressed Rats Fed a High-Fat Diet. $J$ Pharmacol Exp Ther. 2018;364(1):55-69.

This article is protected by copyright. All rights reserved. 
54. Zhou J, Zhang J, Luo X, et al. Neu-P11, a novel MT1/MT2 agonist, reverses diabetes by suppressing the hypothalamic-pituitary-adrenal axis in rats. Eur $J$ Pharmacol. 2017;812:225-233.

55. Dandona P, Aljada A, Chaudhuri A, Mohanty P, Garg R. Metabolic syndrome: a comprehensive perspective based on interactions between obesity, diabetes, and inflammation. Circulation. 2005;111(11):1448-1454.

56. Grattagliano I, Palmieri VO, Portincasa P, Moschetta A, Palasciano G. Oxidative stressinduced risk factors associated with the metabolic syndrome: a unifying hypothesis. $J$ Nutr Biochem. 2008;19(8):491-504.

57. Fisher-Wellman K, Bloomer RJ. Macronutrient specific postprandial oxidative stress: relevance to the development of insulin resistance. Curr Diabetes Rev. 2009;5(4):228238.

58. Matulewicz N, Karczewska-Kupczewska M. Insulin resistance and chronic inflammation. Postepy Hig Med Dosw (Online). 2016;70(0):1245-1258.

59. Monteiro R, Azevedo I. Chronic inflammation in obesity and the metabolic syndrome. Mediators Inflamm. 2010;2010.

60. Meshkani R, Vakili S. Tissue resident macrophages: Key players in the pathogenesis of type 2 diabetes and its complications. Clin Chim Acta. 2016;462:77-89.

61. Fujiwara K, Yatabe M, Tofrizal A, Jindatip D, Yashiro T, Nagai R. Identification of M2 macrophages in anterior pituitary glands of normal rats and rats with estrogen-induced prolactinoma. Cell Tissue Res. 2017;368(2):371-378.

62. Sartori C, Dessen P, Mathieu C, et al. Melatonin improves glucose homeostasis and endothelial vascular function in high-fat diet-fed insulin-resistant mice. Endocrinology. 2009;150(12):5311-5317.

63. Cano Barquilla P, Pagano ES, Jimenez-Ortega V, Fernandez-Mateos P, Esquifino AI, Cardinali DP. Melatonin normalizes clinical and biochemical parameters of mild inflammation in diet-induced metabolic syndrome in rats. J Pineal Res. 2014;57(3):280290.

64. Kitagawa A, Ohta Y, Ohashi K. Melatonin improves metabolic syndrome induced by high fructose intake in rats. J Pineal Res. 2012;52(4):403-413.

65. Belforte NA, Moreno MC, de Zavalia N, et al. Melatonin: a novel neuroprotectant for the treatment of glaucoma. J Pineal Res. 2010;48(4):353-364.

66. Mustonen AM, Nieminen P, Hyvarinen H. Effects of continuous light and melatonin treatment on energy metabolism of the rat. J Endocrinol Invest. 2002;25(8):716-723.

67. Benetti E, Chiazza F, Patel NS, Collino M. The NLRP3 Inflammasome as a novel player of the intercellular crosstalk in metabolic disorders. Mediators Inflamm. 2006;2013:678627.

68. He Y, Hara H, Nunez G. Mechanism and Regulation of NLRP3 Inflammasome Activation. Trends Biochem Sci. 2016;41(12):1012-1021.

69. Netea MG, van de Veerdonk FL, Kullberg BJ, Van der Meer JW, Joosten LA. The role of NLRs and TLRs in the activation of the inflammasome. Expert Opin Biol Ther. 2008;8(12):1867-1872.

70. Rheinheimer J, de Souza BM, Cardoso NS, Bauer AC, Crispim D. Current role of the NLRP3 inflammasome on obesity and insulin resistance: A systematic review. Metabolism. 2017;74:1-9.

71. Legrand-Poels S, Esser N, L'Homme L, Scheen A, Paquot N, Piette J. Free fatty acids as modulators of the NLRP3 inflammasome in obesity/type 2 diabetes. Biochem Pharmacol. 2014;92(1):131-141.

72. Tack CJ, Stienstra R, Joosten LA, Netea MG. Inflammation links excess fat to insulin resistance: the role of the interleukin-1 family. Immunol Rev. 2012;249(1):239-252.

This article is protected by copyright. All rights reserved. 
73. Del Campo JA, Gallego P, Grande L. Role of inflammatory response in liver diseases: Therapeutic strategies. World J Hepatol. 2018;10(1):1-7.

74. Gentilini A, Caligiuri A, Provenzano A, Marra F. Novel Aspects in the Pathogenesis of Nonalcoholic Steatohepatitis. Curr Mol Med. 2016;16(8):710-720.

75. Wada J, Makino H. Innate immunity in diabetes and diabetic nephropathy. Nat Rev Nephrol. 2015;12(1):13-26.

76. Rahim I, Djerdjouri B, Sayed RK, et al. Melatonin administration to wild-type mice and nontreated NLRP3 mutant mice share similar inhibition of the inflammatory response during sepsis. J Pineal Res. 2017;63(1).

77. Liu Z, Gan L, Xu Y, et al. Melatonin alleviates inflammasome-induced pyroptosis through inhibiting NF-kappaB/GSDMD signal in mice adipose tissue. $J$ Pineal Res. 2017;63(1).

78. Yi WJ, Kim TS. Melatonin protects mice against stress-induced inflammation through enhancement of M2 macrophage polarization. Int Immunopharmacol. 2017;48:146-158.

79. Zhang Y, Li X, Grailer JJ, et al. Melatonin alleviates acute lung injury through inhibiting the NLRP3 inflammasome. J Pineal Res. 2016;60(4):405-414.

80. Ma S, Chen J, Feng J, et al. Melatonin Ameliorates the Progression of Atherosclerosis via Mitophagy Activation and NLRP3 Inflammasome Inhibition. Oxid Med Cell Longev. 2018;2018:9286458.

81. Shim DW, Shin HJ, Han JW, et al. A novel synthetic derivative of melatonin, 5-hydroxy2'-isobutyl-streptochlorin (HIS), inhibits inflammatory responses via regulation of TRIFdependent signaling and inflammasome activation. Toxicol Appl Pharmacol. 2015;284(2):227-235.

82. Asaba K, Iwasaki Y, Yoshida M, et al. Attenuation by reactive oxygen species of glucocorticoid suppression on proopiomelanocortin gene expression in pituitary corticotroph cells. Endocrinology. 2004;145(1):39-42.

83. Reiter RJ, Tan DX, Fuentes-Broto L. Melatonin: a multitasking molecule. Prog Brain Res. 2006;181:127-151.

84. Reiter RJ, Tan DX, Manchester LC, Pilar Terron M, Flores LJ, Koppisepi S. Medical implications of melatonin: receptor-mediated and receptor-independent actions. Adv Med Sci. 2007;52:11-28.

85. Johnston JD, Messager S, Barrett P, Hazlerigg DG. Melatonin action in the pituitary: neuroendocrine synchronizer and developmental modulator? J Neuroendocrinol. 2003;15(4):405-408.

86. Wu YH, Zhou JN, Balesar R, et al. Distribution of MT1 melatonin receptor immunoreactivity in the human hypothalamus and pituitary gland: colocalization of MT1 with vasopressin, oxytocin, and corticotropin-releasing hormone. J Comp Neurol. 2006;499(6):897-910.

87. von Gall C, Stehle JH, Weaver DR. Mammalian melatonin receptors: molecular biology and signal transduction. Cell Tissue Res. 2002;309(1):151-162.

88. Juszczak M, Roszczyk M, Kowalczyk E, Stempniak B. The influence od melatonin receptors antagonists, luzindole and 4-phenyl-2-propionamidotetralin (4-P-PDOT), on melatonin-dependent vasopressin and adrenocorticotropic hormone (ACTH) release from the rat hypothalamo-hypophysial system. In vitro and in vivo studies. J Physiol Pharmacol. 2014;65(6):777-784.

89. Fischer C, Mueller T, Pfeffer M, Wicht H, von Gall C, Korf HW. Melatonin Receptor 1 Deficiency Affects Feeding Dynamics and Pro-Opiomelanocortin Expression in the Arcuate Nucleus and Pituitary of Mice. Neuroendocrinology. 2017;105(1):35-43.

This article is protected by copyright. All rights reserved. 
Table 1: Melatonin treatment does not affect biometric or biochemical parameters in control and SRD-treated rats.

\begin{tabular}{cccccc}
\hline & $\mathrm{n}$ & $\begin{array}{c}\text { Serum glucose } \\
(\mathrm{mg} / \mathrm{dl})\end{array}$ & $\begin{array}{c}\text { Serum TAG } \\
(\mathrm{mg} / \mathrm{dl})\end{array}$ & $\begin{array}{c}\text { Serum NEFA } \\
(\mathrm{mM})\end{array}$ & $\begin{array}{c}\text { Body weight } \\
(\mathrm{g})\end{array}$ \\
\hline CONTROL & 12 & $91.2 \pm 1.6$ & $75.5 \pm 4.4$ & $0.68 \pm 0.04$ & $330.5 \pm 8.8$ \\
SRD & 12 & $113.4 \pm 3.4^{* * *}$ & $101.0 \pm 8.8^{*}$ & $1.15 \pm 0.07^{* * *}$ & $356.8 \pm 20.7$ \\
MEL & 12 & $85.4 \pm 5.0$ & $82.4 \pm 4.1$ & $0.75 \pm 0.04$ & $321.0 \pm 25.0$ \\
SRD+MEL & 12 & $107.3 \pm 4.2^{*}$ & $103.4 \pm 8.1^{*}$ & $0.98 \pm 0.05^{* * *}$ & $335.5 \pm 20.4$ \\
\hline
\end{tabular}

Serum levels of glucose, triacylglycerides (TAG) and non-esterified fatty acids (NEFA) were determined in blood samples obtained from rats of each experimental group after three weeks of treatment. Average body weight of rats from each group was determined at the end of the experimental period. Data from three independent experiments performed in quadruplicate are shown as mean $\pm \mathrm{SEM} ;{ }^{*} \mathrm{p}<0.05,{ }^{* *} \mathrm{p}<0.01,{ }^{* * *} \mathrm{p}<0,001 v s$. Control by ANOVA followed by Tukey's post hoc test.

This article is protected by copyright. All rights reserved. 


\section{Figure Legends}

Figure 1: HPA axis activity is increased in rats fed a sucrose rich diet (SRD) for three weeks. Control and SRD-treated rats were analyzed for plasma ACTH (A) and serum corticosterone (B) by a chemiluminiscent immunoassay and RIA respectively. Pituitary relative Pomc mRNA levels were determined by RT-qPCR. Values are expressed as mean \pm SEM, $\mathrm{n}=10(\mathrm{~A}, \mathrm{~B})$ and $\mathrm{n}=5(\mathrm{C})$ animals per group; ${ }^{*} \mathrm{p}<0.05$ and ${ }^{* * * *} \mathrm{p}<0.001$, by unpaired Student's $t$ test. (C) A representative western blot for pituitary ACTH protein levels is shown in (D).

Figure 2: Oxidative stress and inflammatory parameters in the adenohypophysis were normalized by melatonin treatment. A) Lipoperoxide levels, B) catalase activity. Data is shown as mean \pm SEM, $\mathrm{n}=5$ animals per group; ${ }^{*} \mathrm{p}<0.05,{ }^{* *} \mathrm{p}<0.01,{ }^{* * *} \mathrm{p}<0.001$ by ANOVA followed by Tukey's post hoc test. C) Hemeoxygenase-1 expression levels. A representative western blot of 3 independent experiments is shown. D) Immunohistochemical detection of Iba-1 positive cells (green) and the corresponding densitometric analysis on the side. Nuclei were stained with DAPI (blue). Scale bar $=75 \mu \mathrm{m}$. Data is shown as mean \pm SEM of \#Iba1 positive cells in 10 fields/animal. ${ }^{* * *} \mathrm{p}<0.001$ by ANOVA followed by Tukey's post hoc test. E) A representative western blot of three independent experiments showing F4/80 protein levels. F) mRNA relative levels of ILIb and inflammasome components Casp1, Asc, Nalp3, by RT-qPCR. Data is shown as mean $\pm \mathrm{SEM}, \mathrm{n}=4$ animals per group; ${ }^{*} \mathrm{p}<0.05,{ }^{* * *} \mathrm{p}<0.001 \mathrm{vs}$. Control, and ${ }^{\#} \mathrm{p}<0.05,{ }^{\# \#} \mathrm{p}<0.001$ vs. SRD by ANOVA followed by Tukey's post hoc test.

This article is protected by copyright. All rights reserved. 
Figure 3: Melatonin treatment prevents the hyperactivation of the HPA axis induced after three weeks of SRD. A) A representative western blot of pituitary ACTH expression levels is shown below the densitometric analysis of blots from three independent experiments. Data is shown as mean $\pm \mathrm{SEM} ;{ }^{* * *} \mathrm{p}<0.001$ by ANOVA followed by Tukey's post hoc test. B) plasma ACTH concentration was determined by a chemiluminiscent immunoassay, and C) serum corticosterone levels by RIA. Data is shown as mean \pm SEM, $n=10$ animals per group; ${ }^{* * * *} \mathrm{p}<0.001$ by ANOVA followed by Tukey’s post hoc test.

Figure 4: Melatonin prevents stimulation of POMC/ACTH expression in corticotroph cells by conditioned media from activated macrophages. A) Murine J774 macrophage cells were incubated with or without $100 \mathrm{ng} / \mathrm{ml}$ LPS, $7.5 \mathrm{mM}$ D-glucose (D-Glu) and $50 \mathrm{nM}$ melatonin (MEL) for 6 hours. Cells were washed, media was replaced and incubations proceeded for another $18 \mathrm{~h}$. Conditioned media $(\mathrm{CM})$ was collected and stored at $-80^{\circ} \mathrm{C}$. AtT-20 cells were transfected with pPOMC-pGL3 (B) or pкB-LUC (C) and incubated for $24 \mathrm{~h}$ in the presence of CM obtained as shown above. D) AtT-20 cells were incubated as before and ACTH protein levels were analyzed by western blot. Data is shown as mean \pm SEM, $\mathrm{n}=4,{ }^{* *} \mathrm{p}<0.01$, ${ }^{* * *} \mathrm{p}<0.001$ by ANOVA followed by Tukey’s post hoc test.

This article is protected by copyright. All rights reserved. 
Figure 1

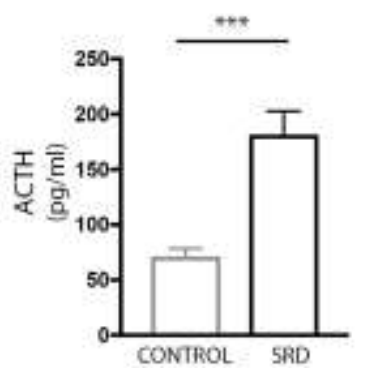

B)

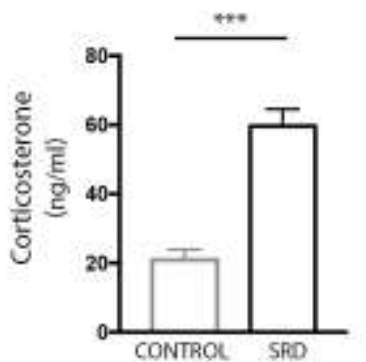

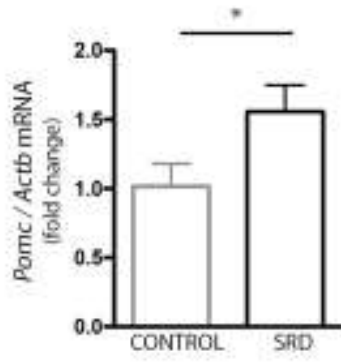

D)

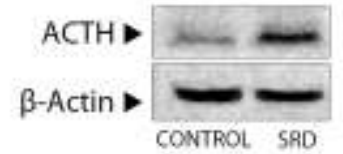

Figure 2

A)

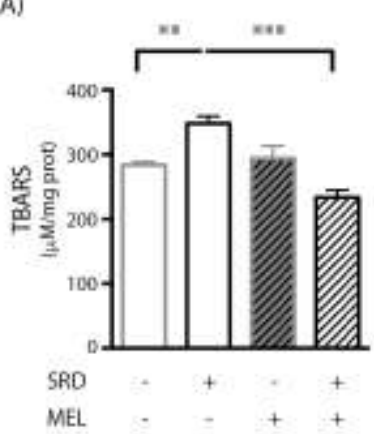

D)

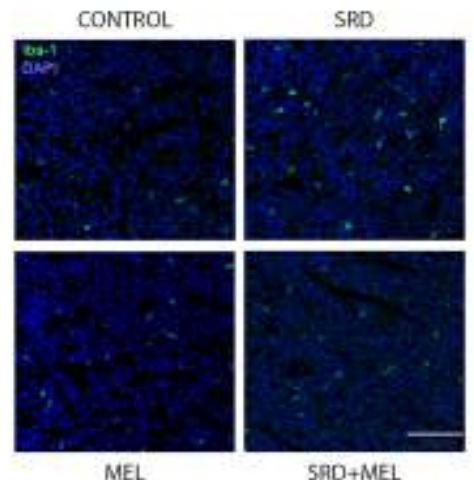

B)
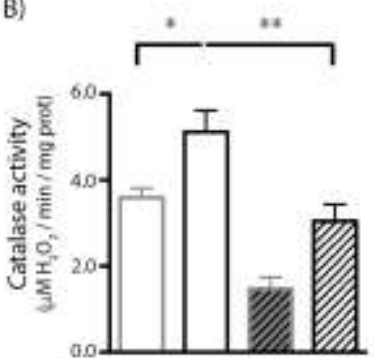

SAD

MEL

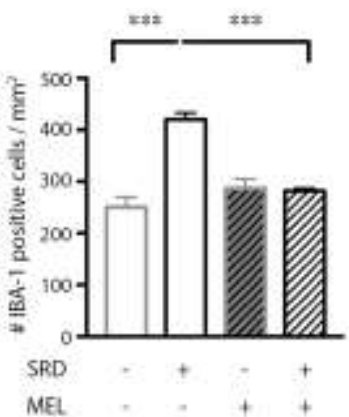

C)

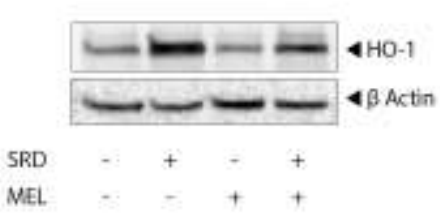

E)

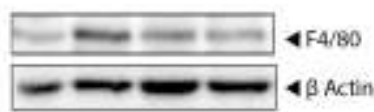

SRO

MEL

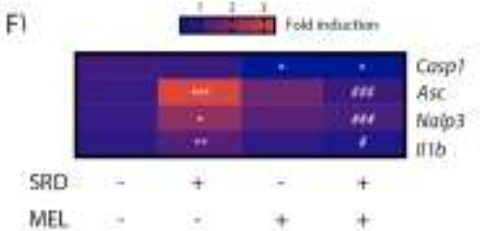

This article is protected by copyright. All rights reserved. 
Figure 3

A)

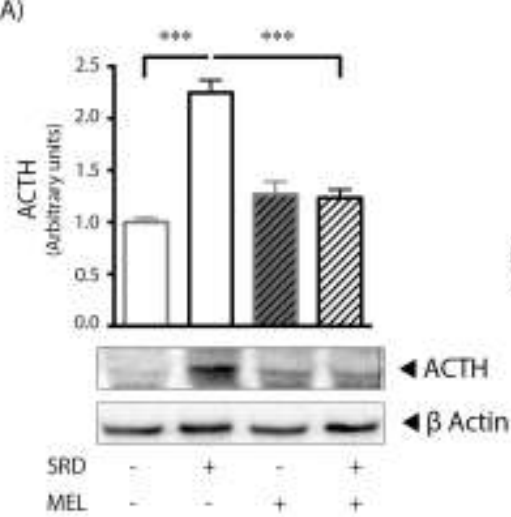

B)

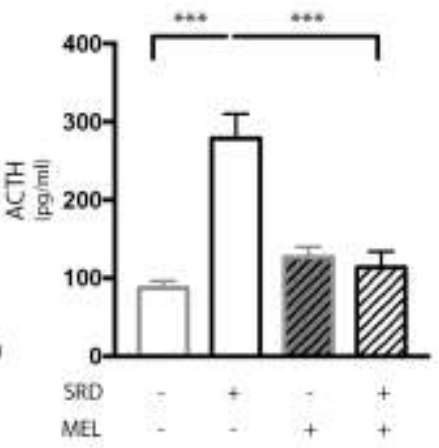

C)

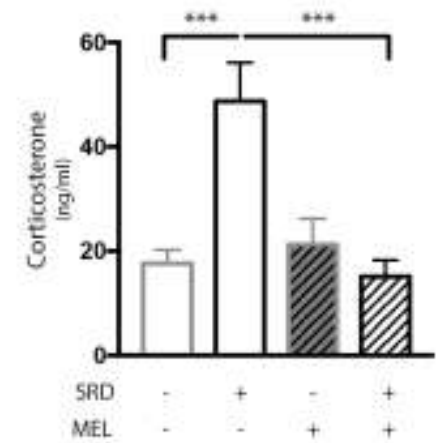

Figure 4

A)

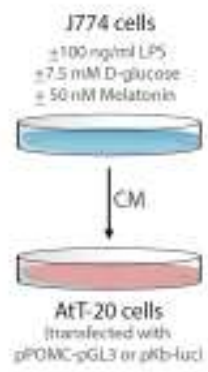

B)

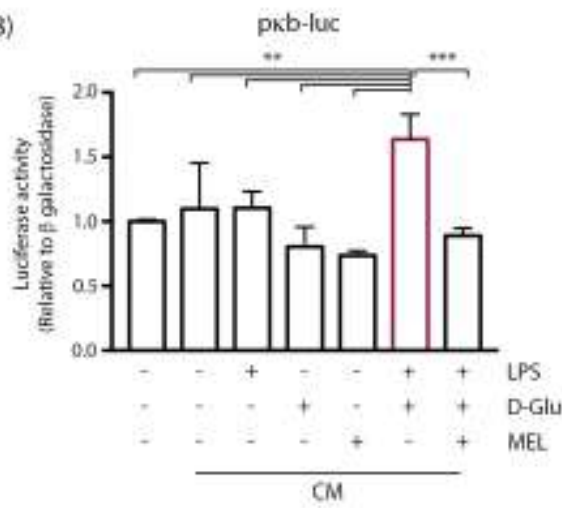

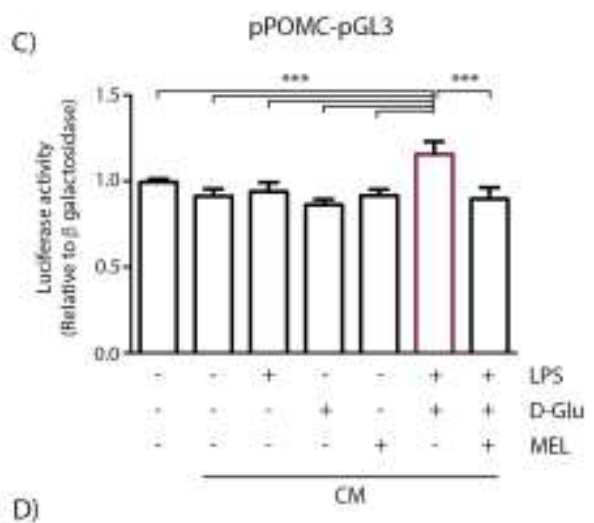

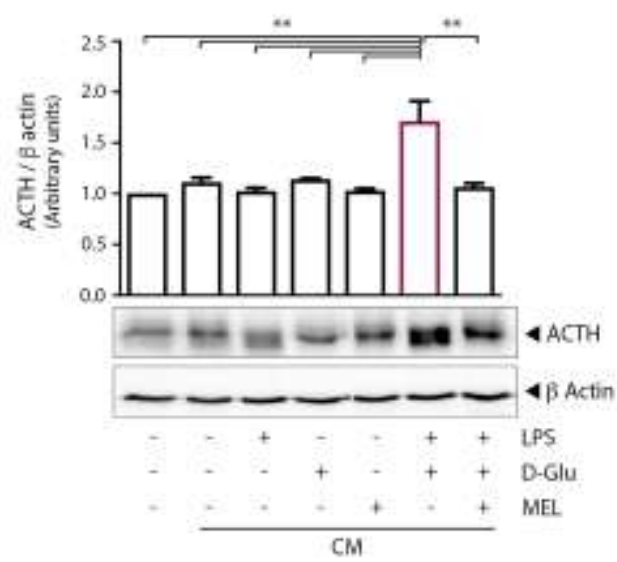

This article is protected by copyright. All rights reserved. 